ARS Sergio José Venancio Júnior*

palavras-chave: arte; inteligência artificial; autonomia; criatividade keywords:

art; artificial intelligence; autonomy; creativity

\section{Arte e inteligências artificiais: implicações para a criatividade.}

\section{Art and Artificial Intelligences: implications for creativity.}

O artigo propõe uma reflexão sobre as obras de arte dotadas de inteligência artificial, tangendo questões como autonomia e criatividade. Primeiro são oferecidas algumas obras como exemplos, e discute-se o problema da autonomia criativa sob a qual estas iniciativas são comumente interpretadas. Referências dos algoritmos evolutivos e da Cibernética culminam em um modelo particular de análise de obras em termos de sintaxe, semântica e pragmática. Tal modelo oferece possível segmentação dos espectros da criatividade humana, enquanto esclarece alguns desafios para o desenvolvimento de máquinas criativas. Finalmente, apresenta-se uma proposta artística que utiliza recursos de inteligência artificial para gerar desenhos, trazendo uma situação em que a máquina influencia, interfere e redefine um processo criativo que dilui intencionalidades do artista.

This article proposes a reflection on the analysis of artworks endowed with artificial intelligence, raising questions such as autonomy and creativity. First, some contemporary artworks are offered as examples while the problem of creative autonomy in which these artworks are commonly interpreted is discussed. References to evolutive algorithms and Cybernetics culminate in a particular model for artwork analysis in terms of syntax, semantics and pragmatics. Such model offers a possible segmentation of the spectra of human creativity, while clarifying some of the current challenges for the development of creative machines. Finally, an artistic proposal is shown, which uses artificial intelligence to make drawings, in a situation in which the machine influences, interferes and redefines a creative process that dilutes the artist's intentionality.

\footnotetext{
*Universidade de São Paulo [USP], Brasil.
}

DOI: 10.11606/issn.2178-0447. ars.2019.152262 


\section{Introdução}

Em janeiro de 2018 foi concluída a exposição "Arte e estética de inteligência artificial” no Instituto Okinawa de Ciência e Tecnologia, em Okinawa, Japão. Tal exposição foi marcada pela seguinte pergunta: poderia uma inteligência artificial realmente produzir arte ${ }^{1}$ ? Para responder a esta questão, os curadores da exposição a dividiram em quatro categorias: (1) Arte Humana/Estética Humana; (2) Arte Humana/ Estética de Máquina; (3) Arte de Máquina/Estética Humana; e (4) Arte de Máquina/Estética de Máquina.

Na primeira categoria a exposição trouxe obras de arte convencionais desde o Renascimento até o Modernismo, buscando mostrar a transformação histórica da estética, que se afastou de questões religiosas e se aproximou da diversidade subjetiva humana. Na segunda categoria encontravam-se obras de arte cuja produção se deu a partir de regras bem definidas ou fórmulas, como muitas obras do Minimalismo a lógica de máquinas e de produção serial alteraram o senso estético humano. A terceira categoria envolveu trabalhos gerados por sistemas de inteligência artificial, como a série Deep Rembrandt, constituída por imagens de pinturas de Rembrandt reinterpretadas por algoritmos de deep dream da empresa Google ${ }^{2}$. O resultado imagético deste caso indica claramente que se trata de reproduções de pinturas icônicas do artista holandês, porém constituídas de figurações translúcidas de animais diversos, como peixes, répteis e aves.

Podemos entender desta terceira categoria que os algoritmos utilizados foram programados conforme objetivos e julgamentos humanos, e isto indica que a inteligência artificial esteve a serviço de uma intenção humana. Isto nos leva ao possível pensamento de que a quarta categoria, finalmente, teria obras geradas a partir de intencionalidades da própria inteligência artificial. No entanto, a quarta categoria não possuía obras, exceto por algumas pequenas pinturas feitas por chimpanzés.

O esvaziamento da quarta categoria nos indica que nenhuma inteligência artificial ainda foi capaz de gerar arte com intenção e estética próprias, e existem dúvidas se algum dia conseguirá fazê-lo. No entanto, o fato de haver pinturas de chimpanzés no local todas abstratas e caóticas para a compreensão humana - serviu para demonstrar como seria a nossa relação com a produção de uma inteligência artificial fazendo arte por motivações próprias. Foi comprovado que chimpanzés conseguem pintar por puro e despretensioso prazer $^{3}$, e não por algum outro objetivo primário, como sobrevivência
184

Sergio José Venancio

Júnior

Arte e inteligências artificiais:

implicações para a criatividade

1. NAKAZAWA, Hideki. Waiting for the Robot Rembrandt.

Nautilus, New York, n. 57, 2018. Disponível em: http://nautil.us/issue/57/ communities/waiting-for-therobot-rembrandt. Acesso em: 3 jul. 2018.

2. Cf. GOOGLE. Deep dream generator. 2017. Disponível em: https:// deepdreamgenerator.com/. Acesso em: 15 nov. 2018.

3. NAKAZAWA, Hideki. Op. cit. 
ou reprodução. De forma análoga se comportariam as inteligências

ก. 35

5. Cf. COHEN, Harold. Aaron's home. 2005. Disponível em: http://www.aaronshome.com. Acesso em: 15 nov. 2018. artificiais com vontade própria.

Para a inteligência artificial chegar ao ponto em que estão os chimpanzés, são necessários dois passos. Primeiro, a inteligência artificial deve ser capaz de gerar seus próprios objetivos. (...) O segundo passo necessário é que a inteligência artificial seja capaz de elevar as metas secundárias - as que existem apenas para servir à sua meta principal - à condição de metas primárias. ${ }^{4}$

Isto significa que, para realmente fazer arte, a inteligência artificial precisaria ter autonomia suficiente para estabelecer seus próprios critérios estéticos, sem qualquer interferência de um humano, e fazê-lo sem que isto esteja subjugado a outros propósitos. A máquina deveria fazer "arte pela arte" e tal questão está em aberto, pois abstrair para a forma de algoritmos os processos de formação de elementos tão subjetivos, como um julgamento estético, não é tarefa simples. E sabemos que um artista adquire tal senso ao longo de sua formação de vida, aprendendo, experimentando, adquirindo habilidades corporais e mentais, evoluindo seus critérios e sua poética. Portanto, será que um dia as inteligências artificiais conseguirão ter autonomia criativa equiparável à de um artista humano? Em busca desta resposta, muitos artistas, também interessados em entender como seria a arte produzida por inteligências artificiais, investigam e experimentam com tais entidades, chegando a resultados bastante provocantes e enriquecedores para a discussão.

\section{Simulações, aprendizados e evoluções}

Uma abordagem que artistas encontraram para fazer as inteligências artificiais gerarem obras inéditas e de alto valor estético reside na simulação computacional de processos comportamentais de artistas humanos. Um dos artistas pioneiros nesta abordagem foi Harold Cohen (1928-2016), criador de Aaron, uma máquina que foi programada ao longo de quatro décadas 5 . Aaron simulou comportamentos de composição, gestual de desenho e pintura, e análise constante de imagens enquanto as produzia. Tais comportamentos permitiram à máquina adquirir independência para desenhar formas figurativas e pintá-las. E embora Aaron gerasse imagens únicas e imprevisíveis, Cohen nunca afirmou que sua obra foi criativa em seus próprios termos, mas apenas dentro das regras que o artista delimitava, indicando que as questões interessantes à arte não estavam nos desenhos produzidos, mas sim nos processos de criar uma máquina geradora de trabalhos artísticos. Ao 
final de sua vida, Cohen pintava os desenhos que Aaron gerava, em uma espécie de sociedade artística entre homem e máquina.

Por outro lado, o artista britânico Simon Colton cria inteligências artificiais que buscam produzir obras com conteúdo convincente o suficiente para que o público credite a máquina como criativa. Sua obra The painting fool ${ }^{6}$, diferente de Aaron, é programada por diferentes pessoas, e o julgamento do público serve de retorno para se especializar o software, enquanto se busca uma estética culturalmente variada e finalmente única em suas produções. Colton confere a seu sistema habilidades de observação através de câmera, análise de imagens por visão computacional e renderizações que se distanciam de imagens fotográficas enquanto se aproximam de resultados de processos manuais. Em um de seus experimentos, o artista e sua equipe treinaram uma inteligência artificial para reconhecer sentimentos no rosto de pessoas retratadas, e refletir isto no estilo do desenho, simulando uma observação sensibilizada. Colton espera que um dia o público possa levar a sério a criatividade de sua máquina, como a de um artista qualquer.

Fazer uma inteligência artificial aprender ao longo do tempo se torna um processo fundamental nesta busca por máquinas que consigam criar de forma autônoma. Técnicas de aprendizado de máquina, como as redes neurais e o deep learning, têm produzido inteligências capazes de absorver o estilo e características de determinadas imagens e reinterpretá-las ou construir outras aplicando o que foi aprendido. O projeto The Next Rembrandt, desenvolvido pela empresa ING em parceria com a Microsoft, envolveu a absorção do estilo e de características de retratos feitos pelo famoso pintor, através de análise formal de imagens e texturas, e treinamento de redes neurais parametrizado por extração de características e proporções faciais, além de paleta de cores, pinceladas e técnicas de luz e sombra típicas do artista $^{7}$. O resultado foi a geração de um novo retrato feito por tecnologias digitais, bastante similar a outras obras originais do pintor.

O tipo de aprendizagem aqui realizado pelas redes neurais é direcionado: humanos oferecem diretrizes sobre o que a máquina deve aprender como estilo, e como ela deve aplicar o estilo adquirido. Trata-se de um dos mais avançados exemplos de inteligência artificial a serviço de uma estética humana, como apontou Nakazawa na terceira categoria da exposição de Okinawa.

Ainda assim, muitos artistas acreditam que é possível fazer inteligências artificiais criarem obras de forma autônoma e com valor estético próprio, sem intervenção humana. $\mathrm{O}$ caminho para tais máquinas neste caso não está apenas na imitação de processos comportamentais
Arte e inteligências artificiais: implicações para a criatividade

6. Cf. COLTON, Simon. The painting fool. 2018. Disponível em: http://www. thepaintingfool.com/. Acesso em: 15 nov. 2018.

7. Cf. ING; MICROSOFT. The Next Rembrandt. 2016. Disponível em: https://www. nextrembrandt.com/. Acesso em: 15 nov. 2018. 
de artistas ou aprendizados supervisionados por humanos, mas princi-

8. Cf. LAURENTIZ, Silvia.

Processos computacionais evolutivos na arte. Ars, São Paulo, v. 1, n. 2 , p. $45-55,2003$.

9. Cf. GALANTER, Philip. Computational aesthetic evaluation: past and future, apud MCCORMACK, Jon; D'INVERNO, Mark. Computers

and creativity. Berlim: Springer, 2012. p. 255-293.

10. Cf. LAURENTIZ, Silvia. Sistemas autônomos, processos de interação e ações criativas. Ars, São Paulo, v. 9, n. 17, p. $101-115,2011$ palmente na abordagem dos sistemas evolutivos, simulando processos de geração de indivíduos por mutação e recombinação, bem como de seleção destes indivíduos, através de função de fitness. Esta função descarta indivíduos que não estão aptos a evoluir, enquanto permite aos sobreviventes se modificarem e recombinarem para as próximas gerações. A cada geração, os indivíduos melhoram dentro do critério de fitness, e com o tempo, a tendência é que evoluam para indivíduos otimizados ${ }^{8}$.

Em um contexto de geração sistêmica de obras de arte, um algoritmo evolutivo considera uma obra que passa por mutação/recombinação de seus constituintes e por processos de seleção das melhores características ao longo do tempo. Uma boa obra seria aquela cujos constituintes "sobreviveram" aos processos seletivos enquanto acumulou as melhores características. Não é difícil perceber que a chave desta abordagem está no próprio critério de fitness e que, neste contexto, tal critério é estético. Se o critério de fitness é estipulado por humanos, mesmo com toda a automação na geração de obras, não há como dizer que existe autonomia criativa para a máquina. Resta o caso em que a função de fitness seria gerada computacionalmente e de forma independente. E uma possível abordagem para que estas funções surjam espontaneamente é relacionada à interação concorrente ou colaborativa entre duas ou mais inteligências artificiais, inseridas em um ambiente propenso a variações ${ }^{9}$. Em outras palavras, um ecossistema de agentes inteligentes que interagem entre si e que se automodificam por razões de sobrevivência ou otimização poderia proporcionar a emergência de critérios de seleção imprevisíveis e, consequentemente, obras imprevisíveis e com estética própria. Veremos a seguir o que está em jogo na análise de autonomia criativa destes agentes.

\section{Cibernética, automação e autonomia}

A Cibernética, definida originalmente como ciência da comunicação e do controle e hoje ampliada para um campo de estudo interdisciplinar dos sistemas complexos e adaptativos, traz a esta discussão os conceitos de cibernética de primeira e de segunda ordem. A de primeira ordem se refere aos sistemas autorreguladores, que possuem um objetivo ou meta e que agem de modo a buscar e manter este objetivo ${ }^{10}$. Estes sistemas são capazes de perceber perturbações nos ambientes em que estão inseridos, enquanto medem constantemente seu desempenho. Se alguma perturbação fizer o sistema se desviar de seu objetivo, ele responderá a estas perturbações e analisará novamente seu desempenho. 
O sistema então se retroalimenta das consequências de suas próprias ações, enquanto verifica se seu desempenho está de acordo com sua meta, e assim repete o ciclo de percepção-ação até atingir o objetivo e manter estabilidade (Fig. 1). Tais sistemas apenas "sobrevivem", pois não há mudanças de objetivo, e sua organização não se modifica, ela apenas reage a diferentes perturbações enquanto busca manter tudo sob controle. Hugh Dubberly classifica estes sistemas como "reativos"11, pois reagem de forma automática, porém previsível. São autômatos.

Já a cibernética de segunda ordem envolve sobreposição de sistemas de primeira ordem: um sistema autorregulador que disponha de um ou mais sistemas autorreguladores e que seja capaz de alterar os objetivos/metas de cada um deles conforme sua própria percepção do ambiente e seu próprio objetivo/meta (Fig. 1). Dubberly chama de "aprendizado" esta relação de observar o ambiente e ajustar os objetivos de primeira ordem conforme um objetivo superior, de segunda ordem. Os sistemas de segunda ordem buscam manter seu objetivo superior enquanto testam diferentes objetivos para seus sistemas de primeira ordem. $\mathrm{O}$ aprendizado ocorre a partir destes testes, quando o sistema pode inferir quais objetivos de primeira ordem são mais ou menos favoráveis ao alcance do objetivo superior, e assim guardar memória destas decisões para o futuro. Estes sistemas são considerados autônomos, pois são capazes de ajustar seus objetivos à necessidade própria. Só é autônomo o sistema capaz de criar condições de autorregulação interna para atingir seu objetivo superior, de forma autorreferente ${ }^{12}$.
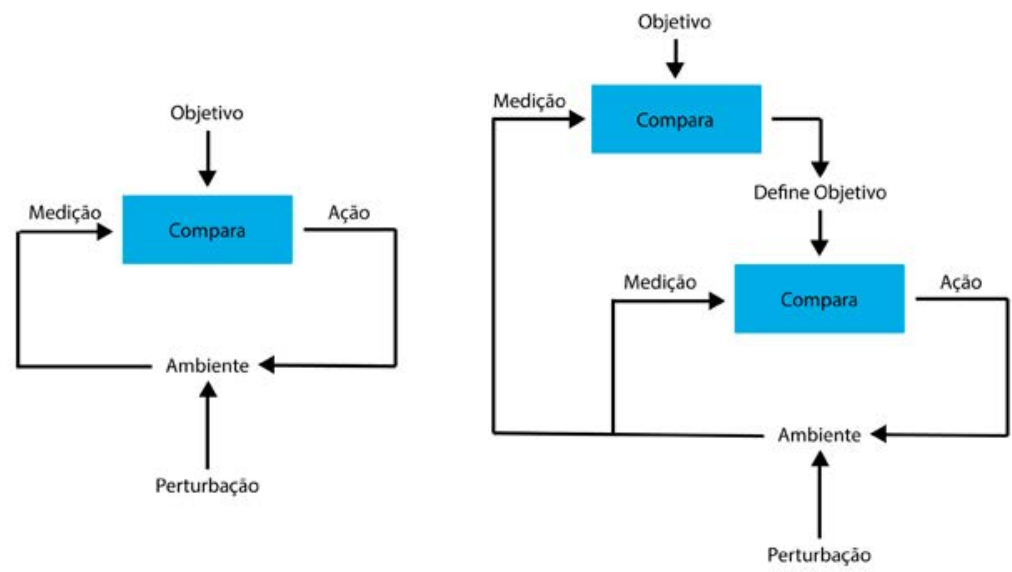

No contexto de inteligências artificiais em propostas artísticas, esta autonomia de um sistema cibernético de segunda ordem por si só ainda não corresponde à autonomia criativa citada anteriormente por Nakazawa, que permitiria à máquina modificar seu
Sergio José Venancio Júnior

Arte e inteligências artificiais:

implicações para a criatividade

11. Cf. DUBBERLY, Hugh; PANGARO, Paul; HAQUE, Usman. What is interaction? Are there different types? 2009. Disponível em: http:// www.dubberly.com/articles/ what-is-interaction.html. Acesso em: 11 jul. 2018.

12. Cf. LAURENTIZ, 2011 , p. 108

Fig 1.

Sistemas cibernéticos de primeira e segunda ordem, respectivamente ladaptado de DUBBERLY, Hugh; PANGARO, Paul; HAQUE, Usman. Op. cit., p. 72, tradução minha). 
objetivo de segunda ordem ou promover trocas entre objetivos pri-

mários e secundários. Uma máquina de segunda ordem precisa de um objetivo constante para nortear o controle dinâmico sobre os sistemas de primeira ordem subordinados a ela. Mesmo existindo memória e aprendizado, estes também são regulados pelo objetivo maior. Qual a natureza, afinal, destes objetivos de segunda ordem para as máquinas? Uma importante constatação é que objetivos de primeira ordem, reativos, podem visar simplesmente a estabilidade, o cumprimento estrito de uma meta, a sobrevivência. Já objetivos de segunda ordem possivelmente incorporam melhorias de situação, de performance ou controle, ou mesmo de reprodução de espécie. Ambos costumam ser claramente parametrizáveis quando aplicados em contextos de inteligências artificiais e sistemas evolutivos. No entanto, um objetivo como "arte pela arte" pode indicar uma busca de lazer/prazer despretensiosa, que não se caracterizaria como estabilidade ou melhoria. Um objetivo estético, totalmente subjetivo, também teria dificuldades para se tornar um objetivo de segunda ordem. Como uma inteligência artificial poderia parametrizar estes tipos de (não) necessidades e operar em prol delas? Ainda, como uma inteligência artificial poderia chegar espontaneamente a uma necessidade desta natureza? Ao pensar nestas diferentes naturezas de objetivos, verifica-se que um sistema de segunda ordem possui autonomia apenas dentro de parâmetros bem definidos, que o permitem verificar como se tornar mais eficiente, ter mais controle, melhorar seus processos, dentre outras coisas. A evolução deste tipo de sistema, portanto, pode ser reduzida a um problema de otimização. E assim também operam os algoritmos evolutivos, nos quais a função de fitness geralmente é dada por parâmetros e resultantes quantificáveis, que culminam na resolução de problemas de otimização. Poderia a criatividade ser reduzida a um problema de otimização?

\section{Heurísticas para a criatividade}

Um ecossistema de agentes inteligentes que interagem entre si parece ser um dos poucos caminhos onde uma inteligência artificial poderia gerar objetivos ou critérios de fitness espontaneamente, pois seu aprendizado e adaptação ocorreriam através de interações com outras inteligências artificiais providas de objetivos muitas vezes distintos. Obviamente, o elemento humano estaria presente nas definições iniciais de tal ecossistema, porém a tendência é que cada agente aprenda e mude seus objetivos internos sem nenhuma intervenção humana, o que 
potencializa as chances de surgirem comportamentos e padrões imprevisíveis e surpreendentes.

Para Peter Cariani, o conceito de "emergência" é útil para observar a criatividade. "Emergência é a aparição de novas entidades que de nenhuma maneira poderiam ser previstas pelo que veio antes"13. Trata-se do surgimento de algo "fundamentalmente novo", em dimensões micro e macro, que faça sentido no âmbito da forma, das estruturas materiais, das organizações, funções, perspectivas e modos de ser. Especificamente quando fala sobre o surgimento de novas perspectivas e formas de ver o mundo, Cariani chama este fenômeno de "emergência epistêmica", e afirma que sua ocorrência decorre do desenvolvimento de novos sensores, naturais ou tecnológicos. O homem desenvolve e amplifica seus sentidos quando, por exemplo, cria próteses sensoriais como termômetros, telescópios e smartphones.

Cariani ainda define como "autonomia epistêmica" a capacidade de uma entidade selecionar seus próprios sensores, sendo um sensor não apenas um mecanismo físico, mas também um ponto de vista, um conceito ou mesmo paradigma. Mais do que isso: para aumentar sua autonomia, a entidade pode exercer emergência epistêmica, desenvolvendo novos sensores, novas formas de percepção e análise, e assim expandir as dimensões de seu espaço de possibilidades. Cariani então sugere que "conceitos de emergência têm alguma utilidade como heurísticas para a criatividade" 14 e que processos emergentes podem ser utilizados para amplificar a criatividade humana.

O autor explica que sistemas complexos são constituídos por um conjunto de partes, e também de regras que combinam tais partes em novas formas. Tais partes, quando atômicas/indivisíveis, são chamadas de "primitivas", pois não são constituídas por combinação de nenhuma outra parte do sistema. Dadas as primitivas e suas regras de combinação, é possível delimitar as dimensões de possibilidades de um sistema complexo. Diante desta definição, Cariani propõe que os processos de criação podem ocorrer por simples recombinação de primitivas, o que o autor chama de "emergência combinatória", ou pela criação de novas primitivas para novas possibilidades de combinação, configurando uma "emergência criativa".

A emergência combinatória constitui uma estratégia criativa e dinâmica à medida que constantemente gera novas combinações de elementos. Entretanto, seu uso de um conjunto fixo de primitivas significa que o conjunto de possibilidades é fechado, ainda que muito amplo. Ao observar os algoritmos evolutivos, Cariani vê um nítido processo de emergência combinatória, dado o caráter de recombinação de pais para
Sergio José Venancio Júnior

Arte e inteligências artificiais: implicações para a criatividade

13. CARIANI, Peter. Emergence and creativity. 2008. Disponível em: http://www.cariani.com/ CarianiNewWebsite/ Publications_files/ CarianiltauCultural2008Emergence.pdf. Acesso em: 10 jul. 2018. p. 1, tradução minha.

14. Ibidem, p. 4, tradução minha, grifo do autor. 
gerar filhos, e um processo de seleção que classifica os indivíduos para que continuem ou não nas próximas gerações. Neste processo evolutivo, as etapas de geração e seleção são classificadas por Cariani como fases de "expansão" e "contração", respectivamente. "A etapa de expansão é o reino da imaginação, de criação livre e aberta, enquanto a fase de contração é o reino da clareza sóbria e do rigor" ${ }^{15}$. Importa notar que, quando a seleção é desempenhada por humanos capazes de julgar ou programar a função de fitness conforme critérios subjetivos, a evolução ao longo das gerações tende a produzir indivíduos alinhados a interesses e objetivos humanos.

Por sua vez, a emergência criativa implica criação de novas primitivas, que, no caso de inteligências artificiais, podem ser representadas pelos sensores. Cariani traz um exemplo de sistema desta vertente na instalação eletroquímica do ciberneticista Gordon Pask ${ }^{16}$, originalmente um mecanismo que formava pontes de limalha de ferro em meio aquoso para condutividade entre diversos eletrodos. As pontes que se mostravam mais sensíveis eram recompensadas, de forma que o sistema aprendeu a formar pontes cada vez mais sensíveis. Inesperadamente, o dispositivo adquiriu a capacidade de distinguir vibrações sonoras que perturbavam a condutividade das pontes em dois níveis de frequência, aos quais o sistema reagia de forma distinta. Pask afirmava que o dispositivo, ainda que de forma rudimentar, desenvolveu um "ouvido" para frequências sonoras; para Cariani isto representou a adição de uma nova primitiva ao sistema, e consequentemente a expansão do espaço de possibilidades. No entanto, o desenvolvimento deste novo "sensor" é ainda combinação de outras primitivas eletroquímicas do sistema. Mesmo após algum tempo de aprendizado e de reações cada vez mais rápidas a estímulos sonoros, o sistema ainda percebe tais perturbações pelos mesmos meios exclusivamente eletroquímicos. Como o autor explica, o novo sensor não necessariamente é um dispositivo físico, mas pode ser um novo conceito, outra forma de ver um problema, e isto se configura como emergência epistêmica. Este novo sensor assume um protagonismo que permitiria ao sistema um pequeno grau de emergência criativa, uma mudança nas formas que a instalação dispõe para perceber o ambiente.

Cariani então propõe um modelo de classificação dos sistemas cibernéticos de acordo com categorias semióticas - sintática, semântica e pragmática - e analisa as manifestações de emergência combinatória e criativa nestas três dimensões. Sintaxe descreve as relações definidas por regras entre as primitivas de um sistema. Semântica envolve a relação das primitivas com o ambiente, considerando as causalidades de 
sensores e atuadores dos sistemas. Pragmática envolve os propósitos do sistema, em que cada objetivo pode ser considerado uma primitiva. A Tabela 1 representa tal modelo:

Tabela 1. Emergência combinatória e criativa em dispositivos cibernéticos ${ }^{17}$

\begin{tabular}{c|c|c|c|c}
\hline Dimensão & Primitivas & $\begin{array}{c}\text { Sistemas } \\
\text { estáveis } \\
\text { (estrutura fixa) }\end{array}$ & $\begin{array}{c}\text { Sistemas } \\
\text { combinatórios } \\
\text { (buscam/ } \\
\text { otimizam } \\
\text { possibilidades } \\
\text { existentes) }\end{array}$ & $\begin{array}{c}\text { Sistemas } \\
\text { criativos } \\
\text { (adicionam } \\
\text { possibilidades, } \\
\text { evoluem) }\end{array}$ \\
\hline Sintática & $\begin{array}{c}\text { Estados, } \\
\text { computações }\end{array}$ & $\begin{array}{c}\text { Autômatos } \\
\text { finitos } \\
\text { determinísticos } \\
\text { (fixos) }\end{array}$ & $\begin{array}{c}\text { Modificam } \\
\text { computações } \\
\text { (máquinas } \\
\text { treináveis) }\end{array}$ & $\begin{array}{c}\text { Novos estados e } \\
\text { regras }\end{array}$ \\
\hline Semântica & Métricas, & $\begin{array}{c}\text { Sensores e } \\
\text { atuadores fixos }\end{array}$ & $\begin{array}{c}\text { Buscam } \\
\text { combinações } \\
\text { de sensores } \\
\text { e atuadores } \\
\text { existentes }\end{array}$ & $\begin{array}{c}\text { Novas métricas } \\
\text { e ações } \\
\text { (autonomia } \\
\text { epistêmica) }\end{array}$ \\
\hline Pragmática & Objetivos & Objetivos fixos & $\begin{array}{c}\text { Buscam } \\
\text { combinações de } \\
\text { objetivos }\end{array}$ & $\begin{array}{l}\text { Novos objetivos } \\
\text { (autodireciona- } \\
\text { mento criativo) }\end{array}$ \\
\hline
\end{tabular}

O modelo classificatório de Cariani se mostra interessante por estabelecer aspectos complementares para entendimento da criatividade. Em contextos de inteligências artificiais, o modelo revela diferentes níveis de autonomia, e possui um importante quesito de análise para o universo de percepção e atuação destas inteligências, que pode ser fechado, nos casos estável e combinatório, ou de "final aberto" no caso criativo. A máquina de Pask, por exemplo, poderia ser considerada criativa no nível semântico, mas não no sintático ou pragmático, pois ela não altera as regras naturais da Eletroquímica, tampouco exerce autodirecionamento criativo - não modifica seu objetivo superior de melhorar as condutividades entre os eletrodos do sistema. É curioso pensar que uma máquina modifica suas relações semânticas com o ambiente a ponto de priorizar a interpretação das perturbações sonoras, criando uma espécie de ouvido. No entanto, a significação de que tal esquema se configura como um ouvido é elaborada por um humano; é ele quem define esta mudança, no papel de observador. Em termos cibernéticos, os sistemas estáveis seriam de primeira ordem, os combinatórios seriam de segunda ordem, e os criativos podem ser interpretados como sistemas de segunda ordem capazes de adquirir novos sensos e modificar seu próprio objetivo superior conforme estas novas percepções de mundo.
Sergio José Venancio

Júnior

Arte e inteligências artificiais: implicações para a criatividade

17. Ibidem, p. 11, tradução minha. 
A visão de Cariani inclui diferentes formas de observar e consinos alerta que, na prática, os resultados de uma máquina criativa dificilmente dirão se o que foi produzido decorreu de emergência combinatória ou criativa ou se terá valor artístico suficiente para ser notável. Ao analisar inteligências artificiais que geram obras de arte, o observador humano precisa investigar o processo de formação destas inteligências, e identificar mudanças sintáticas, semânticas ou pragmáticas ocorridas de forma espontânea, bem como emergências combinatórias ou criativas. Se uma inteligência artificial for capaz de alterar suas regras, modos de percepção e objetivos ao longo do tempo, e se tais alterações não servirem a nenhum propósito maior, finalmente teremos uma condição semelhante à autonomia criativa humana.

\section{Intervenções maquínicas em processos criativos}

Sob o entendimento de que possíveis manifestações de criatividade nas máquinas não garantem valor artístico em suas produções, é preciso olhar para as diferentes maneiras com que artistas interpretam e direcionam o desenvolvimento destas tecnologias. Apresentamos um projeto de pesquisa que propõe o desenvolvimento de uma inteligência artificial inserida em um processo artístico de produção de desenhos. $\mathrm{O}$ projeto Extentio (nome provisório) traz atualmente um software que captura imagens através de uma câmera digital e que, por meio de técnicas de visão computacional, extrai destas imagens informações úteis para a geração automática de retratos desenhados. Entendemos que o desenho é fundamento das Artes Visuais, configurando-se como pensamento antes de ser manifestação expressiva ou registro, sem se limitar a instrumentos e meios clássicos como lápis e papel. Consideramos o uso dos fundamentos da computação e suas capacidades de cálculo, repetição e decisão em alta velocidade de processamento, além de recursos de armazenamento e recuperação de dados, como potenciais e inovadores meios de desenho. A pesquisa procura novas possibilidades e entendimentos das dimensões do desenho e das relações entre homem e máquina.

O algoritmo desenvolvido neste projeto se baseia na simulação de um processo de desenho de rostos humanos por observação, e atualmente consiste em:

- detectar faces em imagens-fonte capturadas pela câmera;

- escolher e enquadrar uma destas faces;

- extrair paleta de cores por análise de histograma; 
- cada cor determina uma "caneta" que traçará com linhas retas curtas sobre uma tela em branco;

- o destino de cada linha se limita à proximidade cromática entre os pixels da imagem-fonte, respeitando a regra de não sobrepor os vértices que conectam linhas;

- reanalisar frequentemente a imagem sendo criada, em busca de uma nova detecção facial;

- parar uma "caneta" caso esta não encontre pixels cromaticamente próximos;

- parar todas as "canetas" quando detectada uma nova face ou caso esgote um tempo predeterminado;

- salvar o desenho em arquivo vetorial;

- reiniciar a detecção de faces para fazer novos retratos.

Alguns resultados podem ser observados nas Figuras 2, 3 e 4.

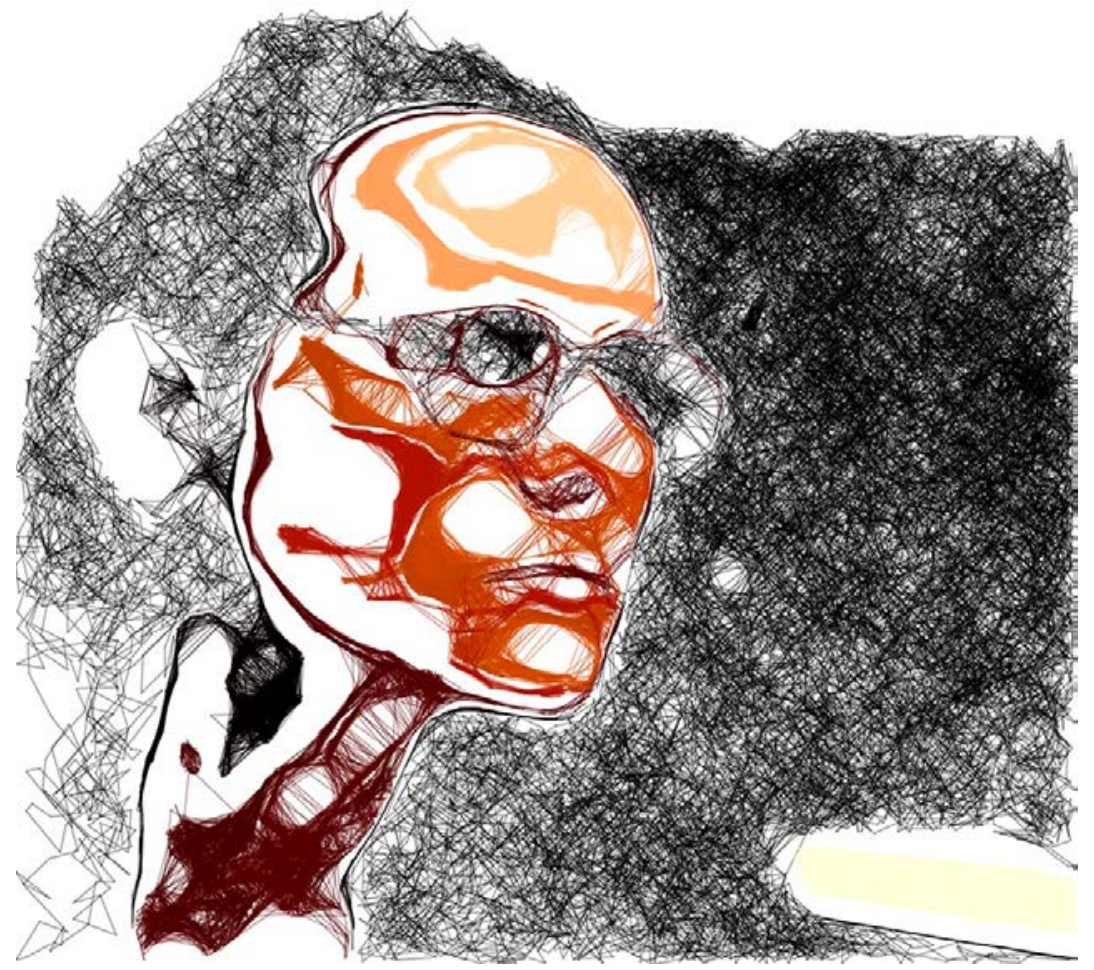

Sergio José Venancio

Júnior

Arte e inteligências artificiais:

implicações para a criatividade
Fig 2.

Retrato 628_952_d14, 2018. Imagem digital, dimensões não definidas 
195

ARS

ano 17

n. 35

Fig 3.

Retrato 621_146_d78, 2018

Imagem digital, dimensões não definidas

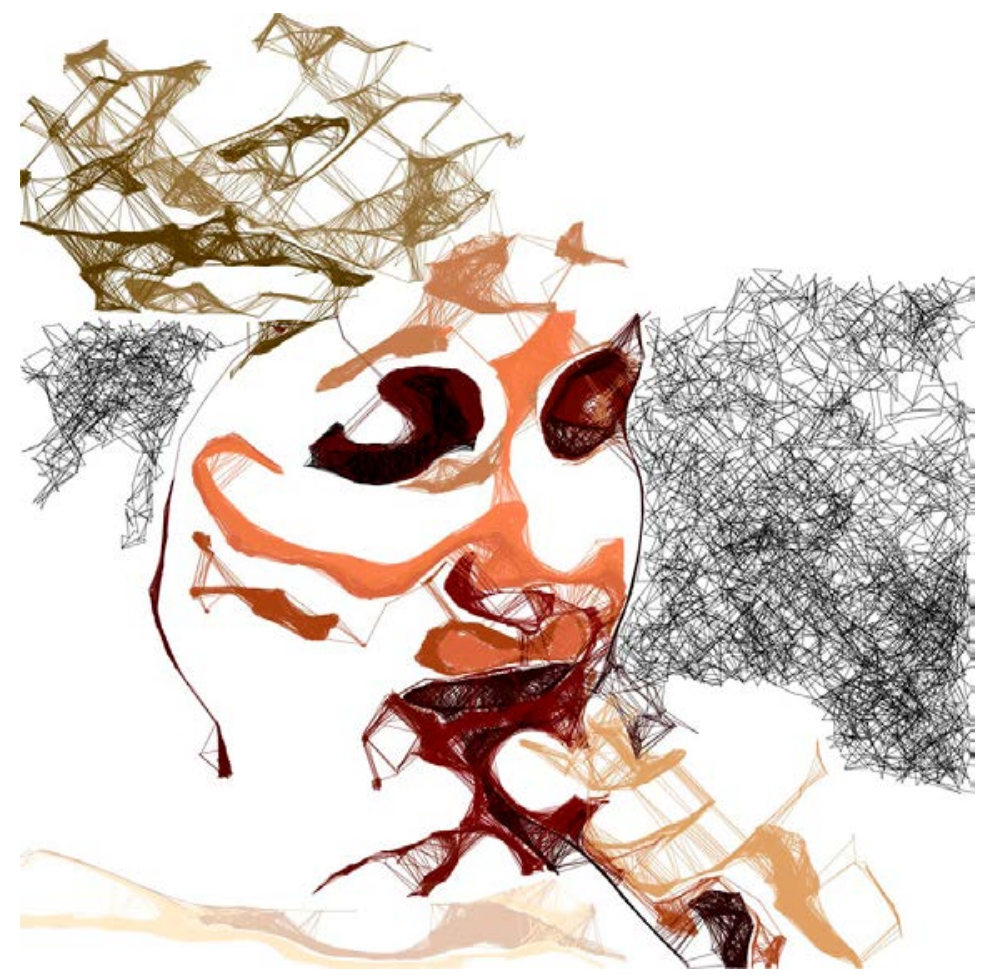

Fig 4.

Retrato 1112_2249_d2, 2018.

Imagem digital, dimensões não definidas

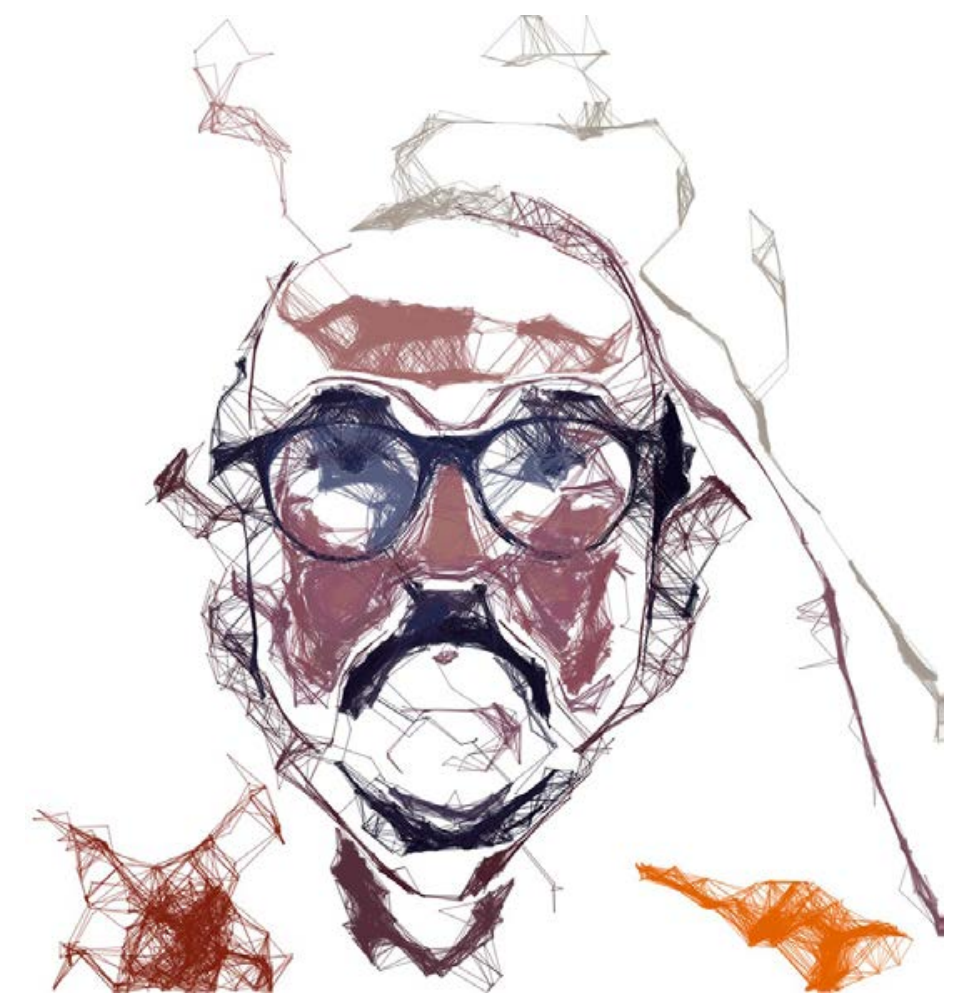


Cada imagem produzida é única, uma vez que as "canetas" tracejam aleatoriamente enquanto concorrem entre si pelo posicionamento irrepetível de vértices sobre a tela em branco. O software possui critério de parada imprevisível, uma vez que a formação de cada retrato não segue um procedimento ordenado, tornando também imprevisível a redetecção facial sobre a imagem em construção, e consequentemente a determinação do fim de um desenho. Todos estes recursos potencializam emergências combinatórias de sensores (câmera, detecção facial) e atuadores (canetas), que resultam em imagens imprevisíveis e surpreendentes, inclusive para o próprio artista dentro de seu processo criativo. Em termos cibernéticos, os objetivos deste sistema estão diluídos a partir do momento em que não há metas rígidas, o que faz com que cada ação e reação do sistema não busque nenhuma estabilidade.

$\mathrm{O}$ projeto Extentio não visa a autonomia criativa da máquina, embora permita atuações cada vez maiores das inteligências artificiais dentro do processo criativo. $\mathrm{O}$ interesse da pesquisa está em perceber como tais inteligências podem influenciar, interferir e redefinir uma produção artística, sem intenções de substituir a figura do artista, mas sim estendendo suas capacidades e amplificando seus processos. $\mathrm{O}$ trabalho de pensar e fazer desenhos através de código segue um ciclo de experimentações conforme o diagrama da Figura 5.

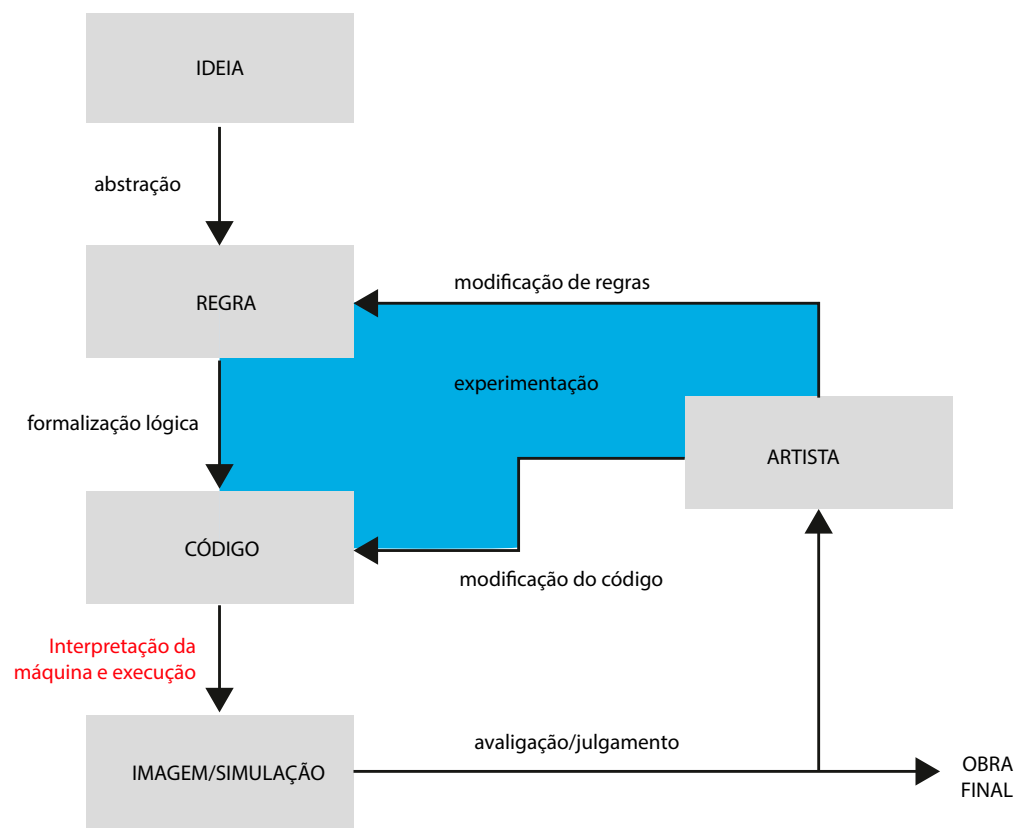

Sergio José Venancio Júnior

Arte e inteligências artificiais: implicações para a criatividade
Fig 5.

Diagrama representativo do processo criativo no projeto Extentio, 2018 
É interesse do projeto buscar novas maneiras pelas quais uma inteligência artificial possa interferir neste ciclo. Hoje, algumas inser-

n. 35 ções do software em processos de avaliação/julgamento já podem ser observadas à medida que o algoritmo avalia constantemente os desenhos sendo feitos para determinar quando parar. Existem atualmente quatro objetivos de desenvolvimento do algoritmo Extentio:

- Observar: trata-se de extrair informações úteis para um desenho de observação, como cores e contrastes, objetos, figurações, faces, corpos. Há bons desenvolvimentos nas áreas de Visão Computacional e Aprendizado de Máquina que poderão ser incorporados a este algoritmo.

- Desenhar: envolve experimentações em código com as informações úteis extraídas anteriormente, convertendo-as em novas visualidades, trabalhando linhas, planos, volumes, luz e sombra, além do "gestual" de desenhos.

- Avaliar: manter constante observação sobre o desenho que vai sendo feito, considerando aspectos de composição como densidades, equilíbrio de cores, posicionamentos e formação de figuras/objetos, portanto as técnicas de Visão Computacional também são úteis aqui. Tais considerações poderão redirecionar os objetivos de observar e desenhar. Hoje, o algoritmo faz uso de detecção facial como critério de parada de um desenho.

- Evoluir: trata da mudança das formas de desenhar ao longo do tempo, e se baseia no aprendizado. Após cada desenho, o sistema deverá receber algum julgamento (externo, de humanos, ou interno, com critérios próprios) que o fará considerar mudar ou manter suas decisões para um próximo desenho. Espera-se que o sistema modifique seu estilo e objetivos de desenho com supervisão do artista, sem perder sua característica de imprevisibilidade.

Estas quatro vertentes de desenvolvimento refletem a absorção dos estudos sobre criatividade em inteligências artificiais. Embora não se busque a máquina autônoma e criativa, os parâmetros de sintaxe, semântica e pragmática propostos por Cariani direcionam os desenvolvimentos propostos e balizam análises sobre como a inteligência artificial pode interferir no processo criativo.

Dentro do objetivo de evoluir, um dos principais desenvolvimentos a implementar futuramente neste projeto envolve o aprendizado de máquina, que permitiria ao sistema considerar cada desenho como um 
experimento parametrizado e absorver dados de cada produção para futuras comparações e tomadas de decisão. Neste cenário, é possível imaginar o sistema modificando ou mesmo estabelecendo novas regras de desenho para assumir papéis ainda maiores neste ciclo. Processos de aprendizado de máquina costumam envolver a supervisão humana, cuja função é avaliar os experimentos e direcionar as futuras interpretações de dados pelo sistema. O papel do artista neste contexto é treinar a inteligência artificial conforme seus interesses, regulando o quanto de si mesmo ele pode conferir ao sistema, ou o quanto pode deixar de delegar, permitindo que surjam emergências combinatórias ou criativas. Trata-se de uma relação homem-máquina que busca novos processos criativos.

\section{Conclusões}

A provocação proposta pela quarta categoria da exposição "Arte e estética de inteligência artificial” no Japão nos aponta uma provável resposta para a questão: podem as inteligências artificiais ser criativas e produzir arte? Sendo otimistas, diríamos que estamos longe desta realidade.

Vimos que, para ser considerada verdadeiramente criativa, uma inteligência artificial deveria ser capaz de gerar espontaneamente seus objetivos e trocá-los conforme a necessidade. A Cibernética nos diz, através dos conceitos de cibernética de primeira e segunda ordem, que os objetivos de uma máquina podem ser hierárquicos e ter focos distintos, como sobrevivência e melhorias. Ela define uma importante distinção para entendermos as inteligências artificiais: automação e autonomia.

(...) é preciso notar que, quando nos deparamos com termos como "edifícios
inteligentes", "agentes inteligentes", "máquinas inteligentes", "dispositivos
inteligentes", estamos diante, na verdade, de sistemas ainda muito aquém
de possuírem autonomia e aprendizagem nos moldes que foram colocados
neste texto. $^{18}$

Mas para fazer arte é preciso outro tipo de objetivo, que pouco teria a ver com estabilidades ou otimizações, mas sim com necessidades de lazer/prazer ou autorrealização. No entanto, a parametrização deste tipo de objetivo é tarefa difícil. Mais do que objetivos, Cariani nos mostra que a autonomia criativa se relaciona com capacidades de adicionar ou alterar regras e estados, métricas, percepções e ações. Sintaxe, semântica e pragmática são elementos complementares que conferem uma imensa complexidade ao assunto criatividade. Se as inteligências artificiais não conseguem estabelecer novas primitivas em todas estas
198

Sergio José Venancio

Júnior

Arte e inteligências artificiais:

implicações para a criatividade
18. LAURENTIZ, Silvia, 2011 , p. 113. 
E quanto aos ecossistemas de agentes inteligentes? Ainda que existam interações de inteligências artificiais que consigam estabelecer novas primitivas sintáticas, semânticas ou pragmáticas, apenas o elemento humano observador é capaz de interpretar tais emergências e significá-las. Significar é processo consciente e criativo que produz e interpreta signos. E o problema da consciência se mostra ainda como um dos maiores argumentos contra uma inteligência artificial ser considerada criativa. Para Fernando Fogliano, tais sistemas:

\footnotetext{
São inteligentes, mas não conscientes. Não podem discernir, julgar conscientemente suas decisões. Podem ser máquinas muito úteis, mas são destituídas de julgamento. Leem mas não entendem, detectam padrões, mas não lhe atribuem significado. Podem substituir humanos em tarefas repetitivas e monótonas apenas. ${ }^{19}$
}

interativa e o inconsciente maquínico. DATJournal, v. 3 , n. 1, p. 39-48, 2018. Disponível em: https://ppgdesign. anhembi.br/datjournal/index. php/dat/article/view/69/60. Acesso em: 19 jul. 2018.

20. NAKAZAWA, Hideki. Op. cit., tradução minha.

No entanto, todas as pesquisas que buscam autonomia criativa para as máquinas o fazem de maneira progressiva, explorando as tecnologias da inteligência artificial para obtenção de resultados imprevisíveis e surpreendentes, muitas vezes inovadores para o campo das artes. A autonomia destas máquinas, porém, está bastante aquém de alcançar o patamar criativo humano, e mesmo que o faça, será inicialmente de forma rudimentar. Em referência às pinturas feitas por chimpanzés e exibidas na quarta categoria da exposição japonesa, Nakazawa aposta: "A verdadeira arte criada por inteligência artificial será ao mesmo tempo dolorosamente entediante e altamente estimulante, e isso representará progresso"20.

Diante destes desafios impostos à criatividade de máquinas inteligentes, fica evidente que a arte nunca se dissocia do elemento humano. O projeto Extentio não busca estabelecer uma máquina totalmente autônoma, mas diferentes formas de as inteligências artificiais afetarem um processo artístico. Aqui, o artista utiliza a linguagem de programação como linguagem expressiva, enquanto delega à máquina decisões constituintes de seu processo. Em contrapartida, a máquina produz imagens de forma experimental e absorve parâmetros para futuras tomadas de decisão que passam a se distanciar das decisões iniciais do artista. Invariavelmente, cabe ao artista significar as emergências, julgar os resultados e retrabalhar o código, em um processo interativo cíclico. Um dos objetivos deste projeto é delegar cada vez mais decisões à máquina, 
buscando nos desenvolvimentos da área de Inteligência Artificial novos recursos que permitam ao artista diluir suas intenções criativas e transformar seu processo criativo em um diálogo sempre renovado com as potencialidades da máquina.

\section{Bibliografia}

BODEN, Margaret A. Creativity \& art: three roads to surprise. Oxford: Oxford University Press, 2011.

CARIANI, Peter. Emergence and creativity. 2008. Disponível em: http://www.cariani.com/CarianiNewWebsite/Publications_files/ CarianiItauCultural2008-Emergence.pdf. Acesso em: 10 jul. 2018.

COHEN, Harold. Aaron's home. 2005. Disponível em: http://www. aaronshome.com. Acesso em: 15 nov. 2018.

COLTON, Simon. The painting fool. 2018. Disponível em: http:// www.thepaintingfool.com/. Acesso em: 15 nov. 2018.

DUBBERLY, Hugh; PANGARO, Paul; HAQUE, Usman. What is interaction? Are there different types? 2009. Disponível em: http://www. dubberly.com/articles/what-is-interaction.html. Acesso em: 11 jul. 2018.

FOGLIANO, Fernando. Arte interativa e o inconsciente maquínico. DATJournal, v. 3, n. 1, p. 39-48, 2018. Disponível em: https://ppgdesign. anhembi.br/datjournal/index.php/dat/article/view/69/60. Acesso em: 19 jul. 2018

GOOGLE. Deep Dream Generator. Disponível em https:// deepdreamgenerator.com/. Acesso em: 15 nov. 2018.

ING; MICROSOFT. The Next Rembrandt. 2016. Disponível em: https://www.nextrembrandt.com/. Acesso em: 15 nov. 2018

LAURENTIZ, Silvia. Processos computacionais evolutivos na arte. Ars, São Paulo, v. 1, n. 2, p. 45-55, 2003.

LAURENTIZ, Silvia. Sistemas autônomos, processos de interação e ações criativas. Ars, São Paulo, v. 9, n. 17, p. 101-115, 2011.
Sergio José Venancio

Júnior

Arte e inteligências artificiais:

implicações para a criatividade 
ARS MCCORDUCK, Pamela. Aaron's code: meta-art, artificial ano 17 intelligence, and the work of Harold Cohen. New York: W. H. Freeman n. 35 and Company, 1990.

MCCORMACK, Jon; D'INVERNO, Mark. Computers and creativity. Berlim: Springer, 2012.

NAKAZAWA, Hideki. Waiting for the Robot Rembrandt. Nautilus, New York, n. 57, 2018. Disponível em: http://nautil.us/issue/57/communities/ waiting-for-the-robot-rembrandt. Acesso em: 3 jul. 2018.

NÖTH, Winfried. Máquinas semióticas. Galáxia, São Paulo, n. 1, p. $51-73,2001$.

Sergio José Venancio Júnior é mestrando no Programa de Pós-Graduação em Artes Visuais da Escola de Comunicações e Artes da Universidade de São Paulo [ECA/USP], onde desenvolve pesquisas sobre a relação entre Artes Visuais e inteligências artificiais. É bacharel em Artes Visuais (2005) e em Ciência da Computação (2011) pela Universidade Estadual de Campinas [Unicamp]. É docente no curso de Especialização em Design novembro de 2018 e aceito em 8 de janeiro de 2019. Gráfico do Instituto de Artes da Unicamp, onde ministra disciplinas e orienta projetos nas áreas de Design de Interfaces e Design de Experiência do Usuário. 